\title{
RESEARCH
}

Open Access

\section{Molasses as a source of carbon dioxide for attracting the malaria mosquitoes Anopheles gambiae and Anopheles funestus}

\author{
Collins K Mweresa ${ }^{1,2}$, Philemon Omusula ${ }^{1}$, Bruno Otieno ${ }^{1}$, Joop JA van Loon², Willem Takken²
} and Wolfgang R Mukabana ${ }^{1,3^{*}}$

\begin{abstract}
Background: Most odour baits for haematophagous arthropods contain carbon dioxide $\left(\mathrm{CO}_{2}\right)$. The $\mathrm{CO}_{2}$ is sourced artificially from the fermentation of refined sugar (sucrose), dry ice, pressurized gas cylinders or propane. These sources of $\mathrm{CO}_{2}$ are neither cost-effective nor sustainable for use in remote areas of sub-Saharan Africa. In this study, molasses was evaluated as a potential substrate for producing $\mathrm{CO}_{2}$ used as bait for malaria mosquitoes.

Methods: The attraction of laboratory-reared and wild Anopheles gambiae complex mosquitoes to $\mathrm{CO}_{2}$ generated from yeast-fermentation of molasses was assessed under semi-field and field conditions in western Kenya. In the field, responses of wild Anopheles funestus were also assessed. Attraction of the mosquitoes to a synthetic mosquito attractant, Mbita blend (comprising ammonia, L-lactic acid, tetradecanoic acid and 3-methyl-1-butanol) when augmented with $\mathrm{CO}_{2}$ generated from yeast fermentation of either molasses or sucrose was also investigated.

Results: In semi-field, the release rate of $\mathrm{CO}_{2}$ and proportion of An. gambiae mosquitoes attracted increased in tandem with an increase in the quantity of yeast-fermented molasses up to an optimal ratio of molasses and dry yeast. More An. gambiae mosquitoes were attracted to a combination of the Mbita blend plus $\mathrm{CO}_{2}$ produced from fermenting molasses than the Mbita blend plus $\mathrm{CO}_{2}$ from yeast-fermented sucrose. In the field, significantly more female An. gambiae sensu lato mosquitoes were attracted to the Mbita blend augmented with $\mathrm{CO}_{2}$ produced by fermenting $500 \mathrm{~g}$ of molasses compared to $250 \mathrm{~g}$ of sucrose or $250 \mathrm{~g}$ of molasses. Similarly, significantly more An. funestus, Culex and other anopheline mosquito species were attracted to the Mbita blend augmented with $\mathrm{CO}_{2}$ produced from fermenting molasses than the Mbita blend with $\mathrm{CO}_{2}$ produced from sucrose. Augmenting the Mbita blend with $\mathrm{CO}_{2}$ produced from molasses was associated with high catches of blood-fed An. gambiae s.l. and An. funestus mosquitoes.

Conclusion: Molasses is a suitable ingredient for the replacement of sucrose as a substrate for the production of $\mathrm{CO}_{2}$ for sampling of African malaria vectors and other mosquito species. The finding of blood-fed malaria vectors in traps baited with the Mbita blend and $\mathrm{CO}_{2}$ derived from molasses provides a unique opportunity for the study of host-vector interactions.
\end{abstract}

Keywords: Carbon dioxide, Sugar, Sucrose, Molasses, Anopheles gambiae, Anopheles funestus, Malaria, Mosquitoes, Attraction, Behaviour

\footnotetext{
* Correspondence: rmukabana@yahoo.co.uk

'International Centre of Insect Physiology and Ecology, P.O. Box 30772-00100,

GPO, Nairobi, Kenya

${ }^{3}$ School of Biological Sciences, University of Nairobi, PO Box 30197-00100, GPO,

Nairobi, Kenya

Full list of author information is available at the end of the article
}

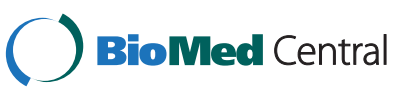

(c) 2014 Mweresa et al.; licensee BioMed Central Ltd. This is an Open Access article distributed under the terms of the Creative Commons Attribution License (http://creativecommons.org/licenses/by/4.0), which permits unrestricted use, distribution, and reproduction in any medium, provided the original work is properly credited. The Creative Commons Public Domain Dedication waiver (http://creativecommons.org/publicdomain/zero/1.0/) applies to the data made available in this article, unless otherwise stated. 


\section{Background}

Female mosquitoes rely mainly on odour cues to locate vertebrate hosts from which they obtain blood meals necessary for egg development [1]. Carbon dioxide $\left(\mathrm{CO}_{2}\right)$ is the cue that is responsible for activating and guiding mosquitoes towards vertebrate hosts [2-4]. For this reason $\mathrm{CO}_{2}$ is commonly added to traps in order to increase mosquito catches during surveillance and/or sampling exercises [5-7]. Previous studies have shown that utilization of $\mathrm{CO}_{2}$ to increase trap catches is dependent on the genetic variability among species, the release rate of the gas and the structure of the host-odour plume [3,8-10]. Several studies have demonstrated that $\mathrm{CO}_{2}$ enhances trap catches of the anthropophilic and anthropophagic malaria vector Anopheles gambiae sensu stricto when released together with human-related odorants [10-12].

Laboratory findings indicated that higher catches of $A n$. gambiae mosquitoes were recorded in traps baited with $\mathrm{CO}_{2}$ combined with skin emanations or ammonia plus L-lactic acid than $\mathrm{CO}_{2}$ alone [9]. Under semi-field conditions, responses of $A n$. gambiae to traps baited with foot odour were greatly increased by adding $\mathrm{CO}_{2}$ [13]. In The Gambia, addition of $\mathrm{CO}_{2}$ to synthetic odours substantially increased the catches of females of all mosquito species collected in MM-X traps [12,14]. In addition, traps baited with $\mathrm{CO}_{2}$ recorded significantly higher numbers of female Anopheles gambiae sensu lato (s.l.) and Anopheles funestus than those without $[3,15]$. In many recent studies $\mathrm{CO}_{2}$ has been incorporated in synthetic odour blends for sampling malaria vectors [16-18].

Artificial sources of $\mathrm{CO}_{2}$ such as fermentation of refined sugar ('sugar/sucrose'), dry ice and $\mathrm{CO}_{2}$ released from pressurized gas cylinders or from propane-powered traps are commonly used in mosquito traps [13,15,19-21]. However, utilization of $\mathrm{CO}_{2}$ from these sources is neither cost-effective nor sustainable for mass deployment of odour-baited devices in remote areas of the tropics. For instance, combustion of propane depends on costly gas tanks that are not widely available in rural sub-Saharan Africa where the greatest burden of malaria occurs. In the tropics, dry ice sublimes faster than in temperate areas and therefore, it has to be replaced more frequently. Where mass trapping is required, the use of industrially produced $\mathrm{CO}_{2}$ stored in pressurized cylinders will be prohibitively expensive. To overcome these limitations, $\mathrm{CO}_{2}$ produced by fermentation of sugar is currently used to supplement synthetic odour-baited MM-X traps for sampling the African malaria vector An. gambiae and other mosquito vectors [11]. Nevertheless, increased cost of living and escalating prices of refined cane sugar in subSaharan Africa call for production of $\mathrm{CO}_{2}$ from cheaper and locally available raw materials.

In this study the possibility of producing $\mathrm{CO}_{2}$ by fermentation of sugar cane molasses (i.e., a by-product formed after crystallization of refined white sugar from the raw juice of crushed sugar cane) instead of refined sugar was explored. The objectives of this study were to: (a) determine average release rates of $\mathrm{CO}_{2}$ produced by fermentation of different quantities of molasses and dry yeast; (b) evaluate the effect of release rates of $\mathrm{CO}_{2}$ on behavioural responses of An. gambiae; (c) evaluate the effect of $\mathrm{CO}_{2}$ produced from molasses on attractiveness of An. gambiae to a previously charatecterized synthetic odour blend; (d) assess the effect of $\mathrm{CO}_{2}$ released from refined sugar and molasses on attractiveness of a synthetic odour blend to An. gambiae; and, (e) evaluate the effect of $\mathrm{CO}_{2}$ released from refined sugar and molasses on attractiveness of a synthetic odour blend to outdoorbiting malaria and other mosquitoes.

\section{Methods}

Semi-field experiments were conducted between April and September 2011 at the Thomas Odhiambo Campus (TOC) of the International Centre of Insect Physiology and Ecology (icipe) located near Mbita Point Township in western Kenya. The experiments were aimed at evaluating molasses as a potential substrate for producing $\mathrm{CO}_{2}$ for use as a bait for malaria mosquitoes.

\section{Mosquitoes}

Laboratory-reared An. gambiae (Mbita strain) mosquitoes were used. Mosquito larvae were raised within a screen-walled greenhouse under ambient climatic conditions. Adult mosquitoes were placed in a holding room under ambient conditions with a photo:scotophase of 12:12 h. Female adult mosquitoes were fed three times a week on blood by direct imbibition from a human arm for $10 \mathrm{~min}$ for egg development. Eggs were laid on moist filter paper and dispensed into plastic trays containing filtered water from Lake Victoria. Newly hatched larvae were transferred into plastic basins and fed on Tetramin ${ }^{\circ}$ baby fish food (Melle, Germany). The larval food was provided three times per day. Pupae were collected daily, placed in clean cups containing filtered water from Lake Victoria and enclosed in mosquito cages. Emerging adult mosquitoes were kept inside cages $(30 \times 30 \times 30 \mathrm{~cm})$ covered by mosquito netting and maintained on $6 \%$ glucose solution delivered on Whatman filter paper wicks. Water was provided on cotton towels placed on top of the mesh-covered cages. A total of 200 females aged three to five days old without prior access to a blood meal were randomly collected from holding cages, placed in a release cup covered with mosquito netting, starved for eight hours and released at the centre of a screen-walled greenhouse at the onset of each experiment (20:00-06:30) [22]. During starvation, mosquitoes were only provided with water on a moistened towel. 


\section{Field study site}

Field studies were carried out in November 2011 at Kigoche village, situated near Ahero town, in the Kano plains of Kisumu County, western Kenya. Kigoche village is located $00^{\circ} 34^{\prime} \mathrm{S}, 34^{\circ} 65^{\prime} \mathrm{E}$ and $1,158 \mathrm{~m}$ above sea level, along the northern boundary of the Ahero rice irrigation scheme [18,23], approximately $110 \mathrm{~km}$ east of the icipe, TOC campus. The area receives between 1,000 and $1,800 \mathrm{~mm}$ of rainfall annually with annual temperature and relative humidity $(\mathrm{RH})$ ranges of $17-32^{\circ} \mathrm{C}$ and 44 $80 \%$, respectively. The long rainy season occurs between March and August while short rains are common in October to November. Irrigated rice farming is the main economic activity. Supplementary traditional farming of maize, millet, bananas, sweet potatoes, beans, cassava, sorghum, and rearing of indigenous cattle, goats, sheep, and poultry is also practiced. During the night cattle, sheep and goats are tethered outdoors adjacent to houses occupied by dwellers. Most houses consist of mud walls, corrugated iron-sheet roofs and have either one or two rooms. The houses typically have open eaves spaces but no ceiling. Malaria is mainly transmitted by An. gambiae, Anopheles arabiensis and An. funestus mosquitoes $[18,23,24]$. These vectors breed predominantly in rice paddies and in both shaded and unshaded irrigation water channels.

\section{Preparation and dispensing of synthetic mosquito odour blend}

Carbon dioxide was produced from a mixture of sucrose obtained locally from refined cane sugar ('sugar') or molasses from sugar cane ('molasses') (Mumias Sugar Company Ltd, Kenya), instant dry yeast ('yeast') (Angel ${ }^{\circ}$ Company, China) and water. The sugar content, total dissolved solids and purity of molasses used were determined at the Kenya Sugar Research Foundation (KESREF) laboratory in Kibos, western Kenya. $\mathrm{CO}_{2}$ from sugar was produced by mixing 250 g sugar, $17.5 \mathrm{~g}$ yeast and $2 \mathrm{~L}$ water $[11,18]$. Molassesproduced $\mathrm{CO}_{2}$ was obtained by mixing $2 \mathrm{~L}$ water with (a) $125 \mathrm{~g}$ molasses and either $8.75 \mathrm{~g}$ or $17.5 \mathrm{~g}$ yeast, (b) $250 \mathrm{~g}$ molasses and $17.5 \mathrm{~g}$ or $35 \mathrm{~g}$ yeast, and (c), $500 \mathrm{~g}$ molasses plus $17.5 \mathrm{~g}$ or $35 \mathrm{~g}$ yeast. Although tap water was used during semi-field experiments, all field bioassays were conducted using locally available clean water from Kigoche village. The ingredients used to produce $\mathrm{CO}_{2}$ were mixed by shaking for $30 \mathrm{sec}$. The process was carried out in $5 \mathrm{~L}$ plastic containers under ambient climatic conditions.

A strip of laboratory Parafilm 'M' (Pechiney Plastic Packaging, Chicago, IL 60631, USA) was tied round the connection points along the $\mathrm{CO}_{2}$ delivery system to prevent leakage. Non-perfumed pure petroleum jelly (Vaseline ${ }^{\mathrm{Ts}}$, Unilever Kenya Ltd) was also applied to prevent leakage. There was no more shaking of ingredients in the container upon commencement of $\mathrm{CO}_{2}$ emission. Released $\mathrm{CO}_{2}$ was delivered through a $60-\mathrm{cm}$ long silicon tubing $(0.5 \mathrm{~cm}$ diameter) into individual MM-X traps (American Biophysics, North Kingstown, RI, USA) and dispensed singly or in combination with a mosquito attractant referred to as the Mbita blend. In this study, the blend contained ammonia (2.5\%), L-lactic acid (85\%), tetradecanoic acid (0.00025\%) and 3-methyl-1-butanol (0.000001\%) each impregnated on a separate nylon strip [25]. The four impregnated nylon strips were hooked together on a wire ring and hung inside the plume tube of a MM-X trap supplied with $\mathrm{CO}_{2}$ from either molasses or sugar. The lower end of the plume tube was suspended $15 \mathrm{~cm}$ above ground level [26]. Although the treated nylon strips for individual sets of experiments were re-used throughout without replacement or replenishment, fresh $\mathrm{CO}_{2}$ was prepared for each experimental replicate [25].

\section{General procedures}

Semi-field experiments were started at 20.00 when it was completely dark. This helped to exclude the possibility of experimental mosquitoes released from the centre of the screen-house from responding to a unidirectional source of light occasioned by sunset. The start of experiments in darkness was not necessary under field conditions (i.e.18:30-06:30) because the wild mosquitoes lured to trapping devices originated randomly from sources located in different directions.

All MM-X traps were operated on $12 \mathrm{~V}$. Vaseline pure petroleum jelly was also applied on suspension wire bars and electrical cables to prevent ants from preying on mosquitoes caught in the MM-X traps. Baited traps and an unbaited MM-X trap were randomly assigned and alternated daily between trap positions to eliminate confounding effects associated with site. A data logger (Tinytag ${ }^{\oplus}$ Ultra, model TGU-1500, INTAB Benelux, the Netherlands) was used to record ambient temperature and $\mathrm{RH}$ at an interval of $30 \mathrm{~min}$. To terminate individual experiments, a plug was inserted into the outer tube of the MM-X trap, the $\mathrm{CO}_{2}$ supply cut off, and power switched off (semi-field) or traps disconnected from batteries (field study). Latex gloves were worn during preparation of refined sugar/molasses-yeast mixtures, nylon strips, application of attractants on nylon strips and baiting of traps to avoid contamination with human volatiles or other odorant compounds. Traps containing mosquitoes were placed in a refrigerator at $-4^{\circ} \mathrm{C}$ for $30 \mathrm{~min}$. Immobilized mosquitoes were collected from each trap, counted and recorded. Thereafter, traps were cleaned using 70\% methanol (to remove residual odours) between experiments. A manual, hand held aspirator was used to collect untrapped, free-flying mosquitoes from the screen-walled greenhouse and killed. The sand-filled floor of the greenhouse was moistened daily to enhance survival of mosquitoes. 


\section{Determination of average release rates of $\mathrm{CO}_{2}$ from molasses}

The relative amounts of molasses and yeast required to produce an optimal quantity of $\mathrm{CO}_{2}$ necessary to elicit significantly high trap catches of $A n$. gambiae were evaluated. The $\mathrm{CO}_{2}$ produced by fermentation of $250 \mathrm{~g}$ sugar mixed with 17.5 g yeast and $2 \mathrm{~L}$ water was used as a reference treatment [11]. On this basis, the quantities of molasses and yeast were halved, doubled or kept similar to those in the reference treatment. Two L of water were used in each treatment. The average volume and duration of $\mathrm{CO}_{2}$ produced by mixing $2 \mathrm{~L}$ water with (a) $125 \mathrm{~g}$ molasses plus $8.75 \mathrm{~g}$ yeast, (b) $125 \mathrm{~g}$ molasses plus 17.5 g yeast, (c) 250 g molasses plus 17.5 g yeast, (d) $250 \mathrm{~g}$ molasses plus $35 \mathrm{~g}$ yeast, (e) $500 \mathrm{~g}$ molasses plus $17.5 \mathrm{~g}$ yeast, and (f) $500 \mathrm{~g}$ molasses plus $35 \mathrm{~g}$ yeast was determined at ambient climatic conditions within a screen-walled greenhouse. The time interval between mixing of ingredients and release of the first bubble of $\mathrm{CO}_{2}$ was also recorded.

A $60-\mathrm{cm}$ long silicon tube $(0.5 \mathrm{~cm}$ diameter $)$ was used to lead $\mathrm{CO}_{2}$ into a calibrated beaker held upside down in a plastic basin containing $10 \mathrm{~L}$ water. The quantity of $\mathrm{CO}_{2}$ released was estimated by measuring and recording volumes of displaced water at intervals of 20 min until the end of each experiment [11]. Individual experiments were replicated four times. A digital stopwatch was used to record the time taken prior to and during $\mathrm{CO}_{2}$ production. The presence of $\mathrm{CO}_{2}$ in the volatile organic compounds (VOCs) produced by fermenting molasses with yeast was confirmed by the formation of a white precipitate of calcium carbonate when the VOCs were passed through a calcium hydroxide solution. Selection of a suitable combination of molasses and yeast for substituting refined sugar as an alternative source of $\mathrm{CO}_{2}$ was based on the length of the release period, volume of $\mathrm{CO}_{2}$ produced, release rate, relative attractiveness to An. gambiae, bulk and cost-effectiveness.

\section{Effect of release rates of $\mathrm{CO}_{2}$ from molasses on catches of Anopheles gambiae}

The attraction of An. gambiae mosquitoes to traps containing different amounts of $\mathrm{CO}_{2}$ produced by varying the quantities of molasses and yeast used as raw materials was compared to those attracted to $\mathrm{CO}_{2}$ derived from sugar. These evaluations were done under semifield conditions. Individual experiments were achieved through dual-choice assays repeated over four nights. The traps assigned for each treatment were placed $10 \mathrm{~m}$ apart in diagonal positions within a screen-walled greenhouse. The total number of mosquitoes caught in two unbaited MM-X traps was also recorded to determine the symmetry of the experimental set up [11,27]. The MM-X traps were baited with $\mathrm{CO}_{2}$ emitted by a mixture of $2 \mathrm{~L}$ water, yeast, and refined sugar or molasses after an incubation period of $30 \mathrm{~min}$ (for $250 \mathrm{~g}$ sugar and $250 \mathrm{~g}$ or $500 \mathrm{~g}$ molasses) or $40 \mathrm{~min}$ (for $125 \mathrm{~g}$ molasses) prior to the onset of each experiment.

\section{Responses of Anopheles gambiae to a synthetic odour blend containing $\mathrm{CO}_{2}$ derived from molasses}

Semi-field experiments were conducted to ascertain whether attraction of $A n$. gambiae mosquitoes to $\mathrm{CO}_{2}$ released separately by two promising combinations of molasses and yeast was enhanced by the addition of the Mbita blend. These combinations were $250 \mathrm{~g}$ molasses plus $17.5 \mathrm{~g}$ yeast, and $500 \mathrm{~g}$ molasses plus $17.5 \mathrm{~g}$ yeast. Therefore, two sets of dual-choice experiments were designed to investigate the responses of $A n$. gambiae to $\mathrm{CO}_{2}$ released from (a) $250 \mathrm{~g}$ molasses, $17.5 \mathrm{~g}$ yeast and $2 \mathrm{~L}$ water alone, versus $250 \mathrm{~g}$ molasses, $17.5 \mathrm{~g}$ yeast and $2 \mathrm{~L}$ water, in conjunction with the Mbita blend, and (b) $500 \mathrm{~g}$ molasses, $17.5 \mathrm{~g}$ yeast and $2 \mathrm{~L}$ water alone, versus 500 g molasses, $17.5 \mathrm{~g}$ yeast and $2 \mathrm{~L}$ water, presented in conjunction with the Mbita blend.

\section{Effect of $\mathrm{CO}_{2}$ released from sugar and molasses on the attractiveness of a synthetic odour blend to Anopheles gambiae}

Follow-up experiments were conducted to evaluate responses of An. gambiae to the Mbita blend augmented singly with $\mathrm{CO}_{2}$ produced by fermentation of $250 \mathrm{~g}$ sugar, $250 \mathrm{~g}$ molasses or $500 \mathrm{~g}$ molasses (each mixed with $17.5 \mathrm{~g}$ yeast and $2 \mathrm{~L}$ water). This was achieved through a complete $4 \times 4$ Latin square experimental design replicated for 16 nights. The treatments included a MM-X trap (i) without odour (control), (ii) Mbita blend plus $\mathrm{CO}_{2}$ released from $250 \mathrm{~g}$ sugar, (iii) Mbita blend plus $\mathrm{CO}_{2}$ emitted from $250 \mathrm{~g}$ molasses, and (iv) Mbita blend plus $\mathrm{CO}_{2}$ released from $500 \mathrm{~g}$ molasses. These semi-field studies were subsequently validated under field conditions.

\section{Responses of wild female malaria vectors}

This study was designed to compare the effect of $\mathrm{CO}_{2}$ produced by fermentation of $250 \mathrm{~g}$ sugar, $250 \mathrm{~g}$ molasses or $500 \mathrm{~g}$ molasses (each mixed with $17.5 \mathrm{~g}$ yeast and $2 \mathrm{~L}$ water) on the attractiveness of the Mbita blend to outdoor-biting malaria and other mosquitoes. The treatments included a MM-X trap (i) without odour, (ii) with Mbita blend containing $\mathrm{CO}_{2}$ emitted from $250 \mathrm{~g}$ sugar, (iii) Mbita blend containing $\mathrm{CO}_{2}$ released from $250 \mathrm{~g}$ molasses, and (iv) Mbita blend containing $\mathrm{CO}_{2}$ derived from $500 \mathrm{~g}$ molasses. A randomized $4 \times 4$ Latin square experimental design replicated over 20 nights was adopted.

Individual treatments were assigned to particular MM-X traps suspended outside the bedroom under the eaves of village houses (Figure 1). Each house was used 


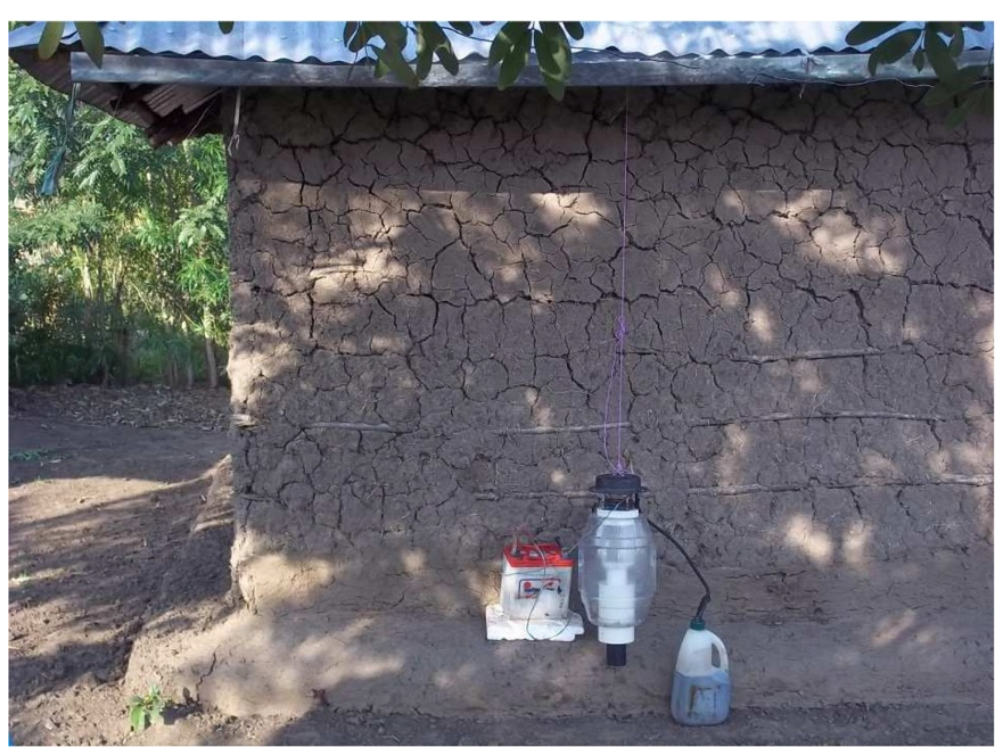

Figure $1 \mathrm{~A}$ picture of an outdoor trapping system baited with the Mbita odour blend augmented with carbon dioxide produced by fermentation of $250 \mathrm{~g}$ molasses using $\mathbf{1 7 . 5} \mathrm{g}$ dry yeast mixed with $\mathbf{2} \mathrm{L}$ water. Carbon dioxide was produced in a plastic container and delivered into the $M M-X$ trap through silicon tubing.

and occupied routinely by two to five dwellers. The dwellers slept under untreated bed nets during experimental nights [12]. The four village houses used in the field experiment were spaced at least $40 \mathrm{~m}$ away from one another. This excluded the potential interaction of treatments placed in any two adjacent houses. Treatments in the $4 \times 4$ Latin square experimental design were allocated with respect to day and position. Thus, individual treatments were rotated between houses every day. One experimental round lasted four days and this equates to 16 days for a fully replicated $4 \times 4$ Latin square experiment.

At the end of each experimental night, all traps were transported to a field laboratory located at the Ahero Multipurpose Development Training Institute (AMDTI) and placed in a freezer for $30 \mathrm{~min}$. The frozen adult mosquitoes were emptied into labeled Petri dishes, identified morphologically [28] counted, and recorded according to (i) sex as male or female An. gambiae s.l., An. funestus, Culex, Mansonia spp. and other anopheline mosquitoes (all collected Anopheles spp. except An. gambiae s.l. and An. funestus) and (ii) external abdominal appearance as unfed, blood-fed (involved fully and partially blood-fed), or gravid females of An. funestus, and An. gambiae s.l. [29]. All female An. gambiae s.l. and An. funestus were preserved in $2 \mathrm{~mL}$ Eppendorf tubes containing silica gel crystals.

\section{Ethical approval}

Scientific and ethical approval of the present study was granted by the Kenya Medical Research Institute (KEMRI/
RES/7/3/1). Inclusion consent of houses into the study was obtained from household heads and the local administration.

\section{Data analysis}

Differences in the release rates of $\mathrm{CO}_{2}$ produced from $250 \mathrm{~g}$ sugar, $125 \mathrm{~g}, 250 \mathrm{~g}$ and $500 \mathrm{~g}$ molasses were determined by using a General Linear Model (GLM), univariate analysis of variance. The Tukey test was used for pairwise comparison of release rates of $\mathrm{CO}_{2}$ from sugar versus $125 \mathrm{~g}, 250 \mathrm{~g}$ and $500 \mathrm{~g}$ molasses. Individual dualchoice bioassays were analyzed using Chi-square tests. The Chi-square test determined whether the distribution of total number of mosquitoes caught in both MM-X traps differed from a 1:1 distribution [11]. Trap counts of mosquitoes collected from experiments conducted through a $4 \times 4$ Latin square design were analysed using a GLM assuming a Poisson distribution and logarithmic link function [22]. The effects of treatment, trap position or house on mosquito catches were tested and fitted as parameters in the model. The significance of trap or house on mosquito catches was fitted with treatment in the model to test for interaction. Effects were considered significant at $\mathrm{P}<0.05$. All analyses were performed using IBM SPSS statistical software, version 16.

\section{Results}

\section{Determination of average release rates of $\mathrm{CO}_{2}$ from} molasses

An average temperature of $23.2 \pm 1.3^{\circ} \mathrm{C}$ and $77.0 \pm 2.6 \%$ $\mathrm{RH}$ were recorded during semi-field experiments (April- 
September 2011). The molasses used in all experiments was $44.7 \%$ pure, and contained $34.2 \%$ sugar and $76.4 \%$ dissolved solids. The release rates of $\mathrm{CO}_{2}$ were dependent on the quantity of molasses used $(\mathrm{P}<0.001)$. Fermentation of $125 \mathrm{~g}, 250 \mathrm{~g}$ and $500 \mathrm{~g}$ molasses emitted $\mathrm{CO}_{2}$ within a time range of 310 to $440 \mathrm{~min}, 490$ to $645 \mathrm{~min}$, and $>840 \mathrm{~min}$, respectively (Figure 2). An increase in the quantity of molasses enhanced release rates and duration of $\mathrm{CO}_{2}$ production. The average postmixing time range for emission of a first bubble of $\mathrm{CO}_{2}$

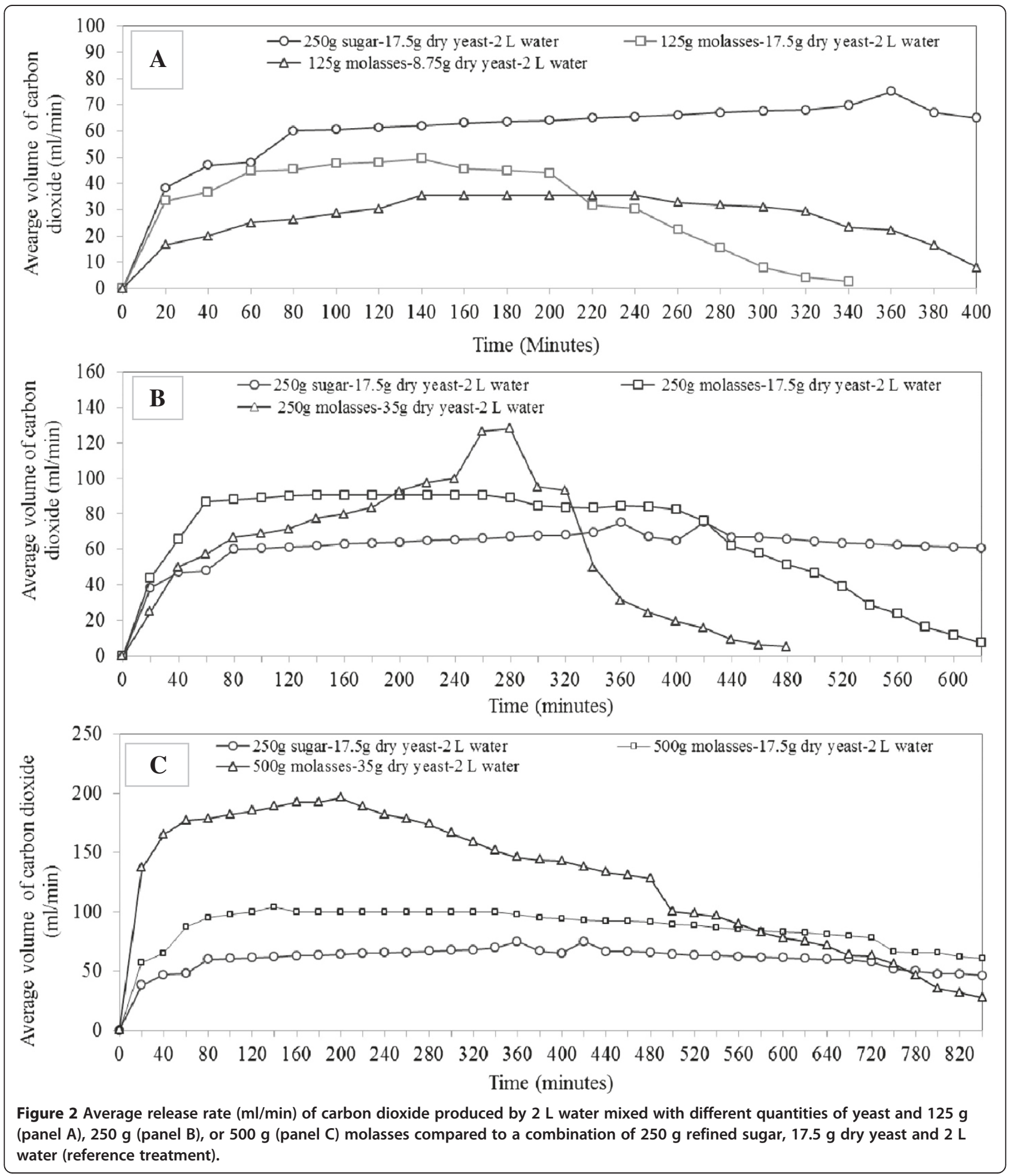


from $125 \mathrm{~g}$, and $250 \mathrm{~g}$ to $500 \mathrm{~g}$ molasses was 29.00$37.50 \mathrm{~min}, 20.00-29.50 \mathrm{~min}$ and $18.35-26.09 \mathrm{~min}$, respectively.

Although release rates of $\mathrm{CO}_{2}$ from $125 \mathrm{~g}$ molasses mixed with $8.75 \mathrm{~g}(36.5 \pm 3.3 \mathrm{ml} / \mathrm{min})$ or $17.5 \mathrm{~g}(30.3 \pm$ $1.6 \mathrm{ml} / \mathrm{min})$ yeast were not different $(\mathrm{P}=0.12)$, the two release rates were significantly lower compared to $250 \mathrm{~g}$ sugar + 17.5 g yeast $(63.23 \pm 2.82 \mathrm{ml} / \mathrm{min}) \quad(\mathrm{P}<0.001)$ (Figure 2A). There was a greater increase in the release rate of $\mathrm{CO}_{2}$ produced by a combination of $250 \mathrm{~g}$ molasses + $17.5 \mathrm{~g}$ yeast $(80.63 \pm 2.82 \mathrm{ml} / \mathrm{min})$ compared to $250 \mathrm{~g}$ sugar or $250 \mathrm{~g}$ molasses $+35 \mathrm{~g}$ yeast $(63.9 \pm 6.6 \mathrm{ml} / \mathrm{min})$ ( $\mathrm{P}=0.010$ for both) (Figure $2 \mathrm{~B})$. By contrast, release rates of $\mathrm{CO}_{2}$ obtained from $250 \mathrm{~g}$ sugar, and $250 \mathrm{~g}$ molasses + $35 \mathrm{~g}$ yeast were not different $(\mathrm{P}=0.10)$. The release rate of $\mathrm{CO}_{2}$ was greatly increased by mixing $500 \mathrm{~g}$ molasses with either $17.5 \mathrm{~g}(87.79 \pm 2.14 \mathrm{ml} / \mathrm{min})$ or $35 \mathrm{~g}(127.4 \pm$ $8.9 \mathrm{ml} / \mathrm{min}$ ) yeast compared to $250 \mathrm{~g}$ sugar $(\mathrm{P}<0.001$ for both) (Figure 2C).

Effect of release rates of $\mathrm{CO}_{2}$ from molasses on catches of Anopheles gambiae

Trap positions had no influence on mosquito catches within the screen-walled greenhouse $(\mathrm{P}=0.11)$. Both traps without odour caught $15.5 \%(\mathrm{n}=124)$ of the released mosquitoes implying that all bioassays were symmetrical. There was a significant increase in the proportions of mosquitoes attracted to $\mathrm{CO}_{2}$ released from $250 \mathrm{~g}$ sugar + $17.5 \mathrm{~g}$ yeast than to a mixture of $125 \mathrm{~g}$ molasses $+8.75 \mathrm{~g}$ yeast $(\mathrm{P}<0.001)$. However, the attractiveness of $\mathrm{CO}_{2}$ produced by fermentation of $250 \mathrm{~g}$ sugar $+17.5 \mathrm{~g}$ yeast, and $125 \mathrm{~g}$ molasses $+17.5 \mathrm{~g}$ yeast to mosquitoes was not different $(\mathrm{P}=0.51)$. A significantly higher proportion of mosquitoes responded to $\mathrm{CO}_{2}$ released from $250 \mathrm{~g}$ molasses +17.5 g yeast compared to $250 \mathrm{~g}$ sugar $+17.5 \mathrm{~g}$ yeast $(\mathrm{P}<0.001)$. By contrast, mosquitoes responded equally to $\mathrm{CO}_{2}$ derived from $250 \mathrm{~g}$ sugar $+17.5 \mathrm{~g}$ yeast and $250 \mathrm{~g}$ molasses +35 g yeast $(\mathrm{P}=0.07)$. Nonetheless, there was a higher response of mosquitoes to $\mathrm{CO}_{2}$ emitted from a mixture of $500 \mathrm{~g}$ molasses $+17.5 \mathrm{~g}$ yeast than to $\mathrm{CO}_{2}$ released from $250 \mathrm{~g}$ sugar $+17.5 \mathrm{~g}$ yeast $(\mathrm{P}=0.001)$. Although the release rate of $\mathrm{CO}_{2}$ from $500 \mathrm{~g}$ molasses $+35 \mathrm{~g}$ yeast was the highest, this combination attracted similar proportions of mosquitoes compared to $250 \mathrm{~g}$ sugar + 17.5 g yeast $(\mathrm{P}=0.11)$. These experiments (Table 1 ) provided the baseline information used to select potential combinations of molasses and yeast for replacement of the currently used $250 \mathrm{~g}$ sugar as a source of $\mathrm{CO}_{2}$ bait for sampling malaria vectors.

\section{Responses of Anopheles gambiae to a synthetic odour blend containing $\mathrm{CO}_{2}$ derived from molasses}

Preceding results indicated that fermentation of $250 \mathrm{~g}$ or $500 \mathrm{~g}$ molasses (each mixed with $17.5 \mathrm{~g}$ yeast and $2 \mathrm{~L}$ water) were promising alternatives for replacing the currently used combination of sugar (250 g), yeast (17.5 g) and water $(2 \mathrm{~L})$ to produce $\mathrm{CO}_{2}$. The responses of mosquitoes to $\mathrm{CO}_{2}$ produced from either $250 \mathrm{~g}$ or $500 \mathrm{~g}$ molasses was significantly increased when released in conjunction with the Mbita odour blend compared to $\mathrm{CO}_{2}$ alone from either quantity ( $\mathrm{P}<0.001$ for both). Of the 272 trapped mosquitoes, $26.1 \%$ were attracted to $\mathrm{CO}_{2}$ released from $250 \mathrm{~g}$ molasses and $73.9 \%$ to the Mbita blend augmented with $\mathrm{CO}_{2}$ derived from $250 \mathrm{~g}$ molasses (Figure 3A). In a similar bioassay, of the 407 mosquitoes collected, $37.1 \%$ were attracted to $\mathrm{CO}_{2}$ emitted from $500 \mathrm{~g}$ molasses, and $62.9 \%$ to the Mbita blend supplemented with $\mathrm{CO}_{2}$ released from $500 \mathrm{~g}$ molasses (Figure 3B).

Effect of $\mathrm{CO}_{2}$ released from sugar and molasses on the attractiveness of a synthetic odour blend to Anopheles gambiae

Out of the 3,200 An. gambiae mosquitoes released, 1,801 (i e, 56.3\%) were trapped during 16 experimental nights. The mosquitoes were collected in traps without odour $(1.4 \%)$ or traps containing the Mbita blend augmented with $\mathrm{CO}_{2}$ released from 250 g sugar (25\%),

Table 1 Total and mean ( \pm SE) number of Anopheles gambiae attracted by carbon dioxide produced in a dual-choice assay in a screen house between molasses treatments (test combinations of molasses and dry yeast dissolved in $2 \mathrm{~L}$ water) and a reference treatment ( $250 \mathrm{~g}$ refined sugar, $17.5 \mathrm{~g}$ dry yeast and $2 \mathrm{~L}$ water)

\begin{tabular}{|c|c|c|c|c|c|}
\hline \multirow[t]{2}{*}{ Molasses treatments } & \multirow[t]{2}{*}{$\mathbf{N}$} & \multirow[t]{2}{*}{$\mathbf{n}$} & \multicolumn{2}{|c|}{ Mean \pm SE number of mosquitoes attracted } & \multirow[t]{2}{*}{ P-value } \\
\hline & & & Molasses treatment & Reference treatment & \\
\hline $125 \mathrm{~g}$ molasses $-17.5 \mathrm{~g}$ yeast $-2 \mathrm{~L}$ water & 4 & 507 & $61.5 \pm 4.0$ & $65.3 \pm 4.0$ & 0.51 \\
\hline $125 \mathrm{~g}$ molasses - $8.75 \mathrm{~g}$ yeast - $2 \mathrm{~L}$ water & 4 & 417 & $35.8 \pm 3.0$ & $68.5 \pm 4.1$ & 0.001 \\
\hline $250 \mathrm{~g}$ molasses - $17.5 \mathrm{~g}$ yeast - $2 \mathrm{~L}$ water & 4 & 460 & $70 \pm 4.2$ & $45.0 \pm 3.4$ & 0.001 \\
\hline $250 \mathrm{~g}$ molasses - $35 \mathrm{~g}$ yeast - $2 \mathrm{~L}$ water & 4 & 371 & $50.8 \pm 3.6$ & $42.0 \pm 3.2$ & 0.07 \\
\hline $500 \mathrm{~g}$ molasses - $17.5 \mathrm{~g}$ yeast - $2 \mathrm{~L}$ water & 4 & 545 & $79.3 \pm 4.5$ & $57.0 \pm 3.8$ & 0.001 \\
\hline $500 \mathrm{~g}$ molasses - $35 \mathrm{~g}$ yeast - $2 \mathrm{~L}$ water & 4 & 440 & $50.8 \pm 3.6$ & $59.3 \pm 3.9$ & 0.11 \\
\hline
\end{tabular}

$\mathrm{N}$ is the number of experimental nights, $\mathrm{n}$ is the total number of mosquitoes caught whereas $\mathrm{SE}$ is the standard error of the mean catch per night. A total of 200 female An. gambiae were released per night. Pairwise comparisons in the same row of mean catches differ significantly at $\mathrm{P}<0.05$ (Chi-square test). 

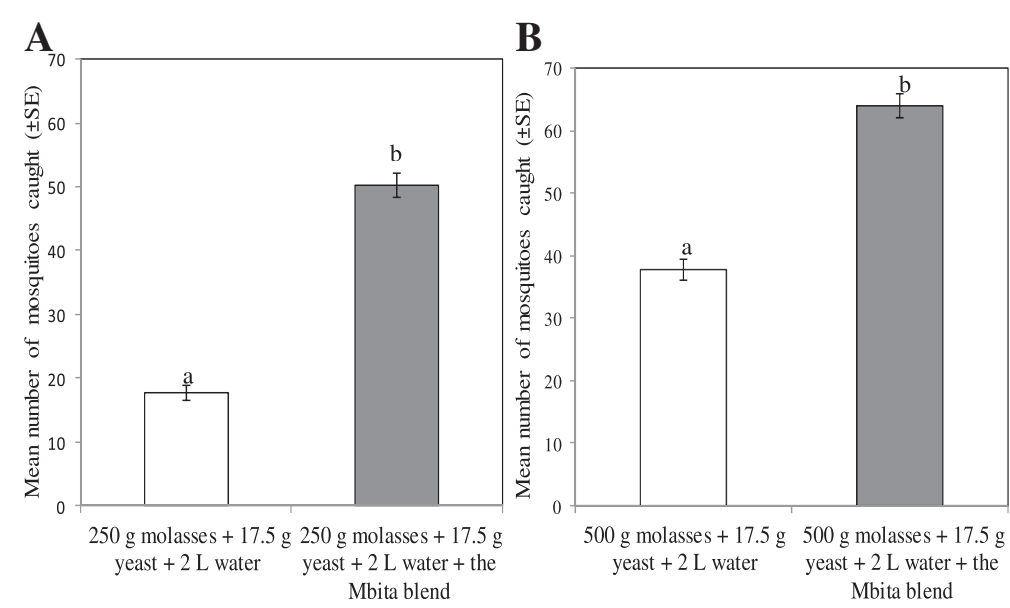

Figure 3 Effect of adding the Mbita odour blend to carbon dioxide produced by fermentation of $250 \mathrm{~g}$ (panel A) and $500 \mathrm{~g}$ (panel B) molasses on the mean number $( \pm \mathrm{SE})$ of Anopheles gambiae collected for four nights. A total of 200 female An. gambiae were released per night within a screen-walled greenhouse. Bars with different letters in the same graph differ significantly $(P<0.05)$. Error bars represent the standard error of the mean number of mosquitoes collected.

250 g molasses (33.9\%) or 500 g molasses (38.9\%) (Table 2). Addition of $\mathrm{CO}_{2}$ from $250 \mathrm{~g}$ molasses to the Mbita blend attracted more mosquitoes than when the Mbita blend was combined with $\mathrm{CO}_{2}$ from $250 \mathrm{~g}$ sugar ( $P<0.001)$. Similarly, the attractiveness of the Mbita blend was significantly increased by adding $\mathrm{CO}_{2}$ produced by fermentation of $500 \mathrm{~g}$ molasses than from $250 \mathrm{~g}$ sugar $(\mathrm{P}<0.001)$. The attractiveness of the Mbita blend was greatly enhanced by the addition of $\mathrm{CO}_{2}$ released from $500 \mathrm{~g}$ fermenting molasses than $250 \mathrm{~g}$ molasses $(\mathrm{P}<0.014)$.

\section{Responses of wild female malaria vectors}

The 20 nights of field experiments (November 2011) were characterized by a mean temperature of $23.5 \pm 2.2^{\circ} \mathrm{C}, 71.9 \pm$ $1.9 \% \mathrm{RH}$, wind speed of $3.2 \pm 0.09 \mathrm{~km} / \mathrm{h}$, and total rainfall of $263.4 \mathrm{~mm}$. A total of 1,807 mosquitoes were caught outdoors. Of this number, $11.2 \%(n=203)$ were males and $88.7 \%(n=1,604)$ were females. Both treatment and house effects played an important role in influencing trap collections of all female mosquitoes $(\mathrm{P}<0.001$ for both). The
1,604 female mosquitoes were collected in traps without odour (2.9\%), baited with the Mbita blend supplemented with $\mathrm{CO}_{2}$ released by fermenting $250 \mathrm{~g}$ sugar (22.6\%), fermenting $250 \mathrm{~g}$ molasses (35.0\%) and fermenting $500 \mathrm{~g}$ molasses (39.5\%) (Figure 4). The female mosquitoes comprised An. gambiae s.l. (18.1\%), An. funestus (20.2\%), Culex spp. (37.8\%), Mansonia spp. (10.2\%) and other anophelines (13.6\%).

Trap collections of female $A n$. gambiae s.l. and $A n$. funestus were influenced by the carbohydrate source of $\mathrm{CO}_{2}$ presented with the Mbita blend ( $\mathrm{P}<0.001$, for both). Addition of $\mathrm{CO}_{2}$ released from $500 \mathrm{~g}$ molasses to the Mbita blend attracted the highest number of An. gambiae s.l. compared to either $\mathrm{CO}_{2}$ derived from $250 \mathrm{~g}$ molasses ( $\mathrm{P}<0.001)$ or from $250 \mathrm{~g}$ sugar $(\mathrm{P}<0.001)$. However, addition of $\mathrm{CO}_{2}$ released from $250 \mathrm{~g}$ molasses or $250 \mathrm{~g}$ sugar on the Mbita blend caused no significant difference on trap collections of An. gambiae s.l. $(\mathrm{P}=0.32)$.

There was a great increase in the responses of $A n$. funestus to the Mbita blend supplemented with $\mathrm{CO}_{2}$ released from $500 \mathrm{~g}$ or $250 \mathrm{~g}$ molasses than to $250 \mathrm{~g}$ sugar

Table 2 Total and mean ( \pm SE) number of Anopheles gambiae caught in a screen house using a MM-X traps without odour, baited with the Mbita odour blend (MB) augmented with carbon dioxide produced by fermentation of either $250 \mathrm{~g}$ refined sugar, $250 \mathrm{~g}$ or $\mathbf{5 0 0} \mathrm{g}$ molasses by using dry yeast

\begin{tabular}{|c|c|c|c|}
\hline \multirow[t]{2}{*}{ Treatment } & \multirow[t]{2}{*}{$\mathbf{N}$} & \multicolumn{2}{|c|}{ Mosquitoes caught } \\
\hline & & n & Mean ( \pm SE) \\
\hline No odour & 16 & 25 & $1.7 \pm 0.3^{\mathrm{a}}$ \\
\hline $250 \mathrm{~g}$ refined sugar - $17.5 \mathrm{~g}$ yeast $-2 \mathrm{~L}$ water and Mbita blend & 16 & 465 & $28.8 \pm 1.3^{b}$ \\
\hline $250 \mathrm{~g}$ molasses - $17.5 \mathrm{~g}$ yeast - $2 \mathrm{~L}$ water and Mbita blend & 16 & 611 & $37.8 \pm 1.5^{c}$ \\
\hline $500 \mathrm{~g}$ molasses $-17.5 \mathrm{~g}$ yeast $-2 \mathrm{~L}$ water and Mbita blend & 16 & 700 & $43.4 \pm 1.6^{d}$ \\
\hline
\end{tabular}

$\mathrm{N}$ is the number of experimental nights, $\mathrm{n}$ is total number of mosquitoes caught whereas SE is the standard error of the mean catch per night. A total of 200 female An. gambiae were released per night. Mean catches in the same column with different superscript letters differ significantly at $P<0.05$ (Generalized Linear Models). 


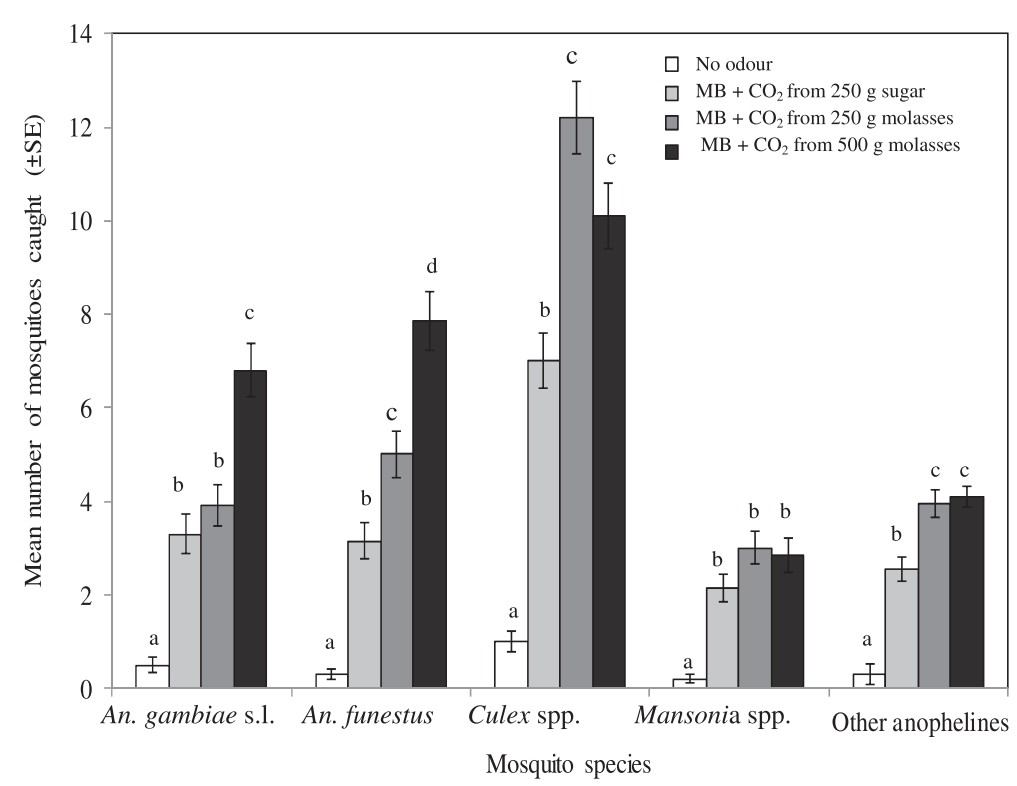

Figure 4 Mean number $( \pm S E$ ) of female mosquitoes caught overnight outdoors in MM-X trap without odour, baited with the Mbita blend (MB) augmented with carbon dioxide produced by fermentation of either $250 \mathrm{~g}$ refined sugar or $250 \mathrm{~g}$ and $500 \mathrm{~g}$ molasses. Mean values within the same mosquito type with different letters are significantly $(P<0.05)$ different.

( $\mathrm{P}<0.001$ and $\mathrm{P}<0.007$, respectively). Nonetheless, the Mbita blend was more attractive to An. funestus when augmented with $\mathrm{CO}_{2}$ derived from $500 \mathrm{~g}$ than $250 \mathrm{~g}$ molasses $(\mathrm{P}<0.01)$. Combinations of the Mbita blend and $\mathrm{CO}_{2}$ released from $250 \mathrm{~g}$ or $500 \mathrm{~g}$ molasses were equally attractive to Culex spp. $(\mathrm{P}=0.12)$ and other anopheline mosquitoes $(\mathrm{P}=0.18)$. However, attractiveness of the Mbita blend supplemented with $\mathrm{CO}_{2}$ from $250 \mathrm{~g}$ sugar to Culex spp. was significantly lower compared to $250 \mathrm{~g}$ $(\mathrm{P}<0.001)$ or $500 \mathrm{~g}(\mathrm{P}<0.010)$ molasses. By contrast, trap collections of Mansonia spp. were not dependent on the carbohydrate source of $\mathrm{CO}_{2}(\mathrm{P}=0.42)$.

A combination between the Mbita blend and $\mathrm{CO}_{2}$ produced by fermentation of molasses elicited a physiological, stage-dependent behaviour of local malaria vectors. The 290 females of An. gambiae s.l. collected were unfed (57.6\%), blood-fed (33.8\%) or gravid (8.6\%) (Figure 5A). The responses of unfed An. gambiae s.l. to the Mbita blend were significantly increased by addition of $\mathrm{CO}_{2}$ derived from $500 \mathrm{~g}$ molasses compared to $250 \mathrm{~g}$ molasses $(\mathrm{P}<0.012)$ or $250 \mathrm{~g}$ sugar $(\mathrm{P}<0.001)$. There was no difference in the responses of unfed An. gambiaes s.l. to the Mbita blend supplemented with $\mathrm{CO}_{2}$ released from either $250 \mathrm{~g}$ molasses or $250 \mathrm{~g}$ sugar $(\mathrm{P}=0.73)$.

A higher mean number of blood-fed An. gambiae s.l. was attracted to the Mbita blend augmented with $\mathrm{CO}_{2}$ emitted from $500 \mathrm{~g}$ molasses than from $250 \mathrm{~g}$ sugar $(\mathrm{P}<0.001)$ or from $250 \mathrm{~g}$ molasses $(\mathrm{P}<0.001)$. Also, the attractiveness of the Mbita blend to blood-fed An. gambiae s.l. was significantly enhanced by addition of $\mathrm{CO}_{2}$ released from $250 \mathrm{~g}$ molasses compared to $250 \mathrm{~g}$ sugar
( $\mathrm{P}<0.034)$. Treatment had no effect on trap catches of gravid An. gambiae s.l. ( $\mathrm{P}=0.34)$.

The 324 females of $A n$. funestus collected were unfed (51.2\%), blood-fed (36.1\%) or gravid (12.6\%) (Figure 5B). The attraction of unfed An. funestus to the Mbita blend was greatly enhanced by addition of $\mathrm{CO}_{2}$ derived from $250 \mathrm{~g}$ or $500 \mathrm{~g}$ molasses compared to $250 \mathrm{~g}$ sugar $(\mathrm{P}<0.013$ and $\mathrm{P}<0.001$, respectively). However, responses of gravid $A n$. funestus to the Mbita blend supplemented with $\mathrm{CO}_{2}$ released from $250 \mathrm{~g}$ molasses or from $250 \mathrm{~g}$ sugar were not different $(\mathrm{P}=0.49)$. By contrast, significantly more gravid An. funestus were attracted to the Mbita blend augmented with $\mathrm{CO}_{2}$ produced by fermentation of $500 \mathrm{~g}$ molasses compared to 250 g sugar $(P<0.014)$. Although baited traps collected high numbers of blood-fed $A n$. funestus, the catches were not statistically different $(\mathrm{P}=0.14)$.

\section{Discussion}

The findings of this study indicate that $\mathrm{CO}_{2}$, and possibly other volatiles, produced by fermentation of molasses provide a suitable alternative to the $\mathrm{CO}_{2}$ obtained from fermentation of the more expensive, refined cane sugar to lure malaria vectors towards traps. The release rate and proportion of An. gambiae mosquitoes caught increased consistently as the quantity of yeast-fermented molasses increased up to an optimal ratio of molasses and yeast. The attraction of mosquitoes to traps baited with $\mathrm{CO}_{2}$ produced by fermenting molasses was enhanced when presented jointly with the Mbita blend of synthetic odours. More malaria vectors and female 

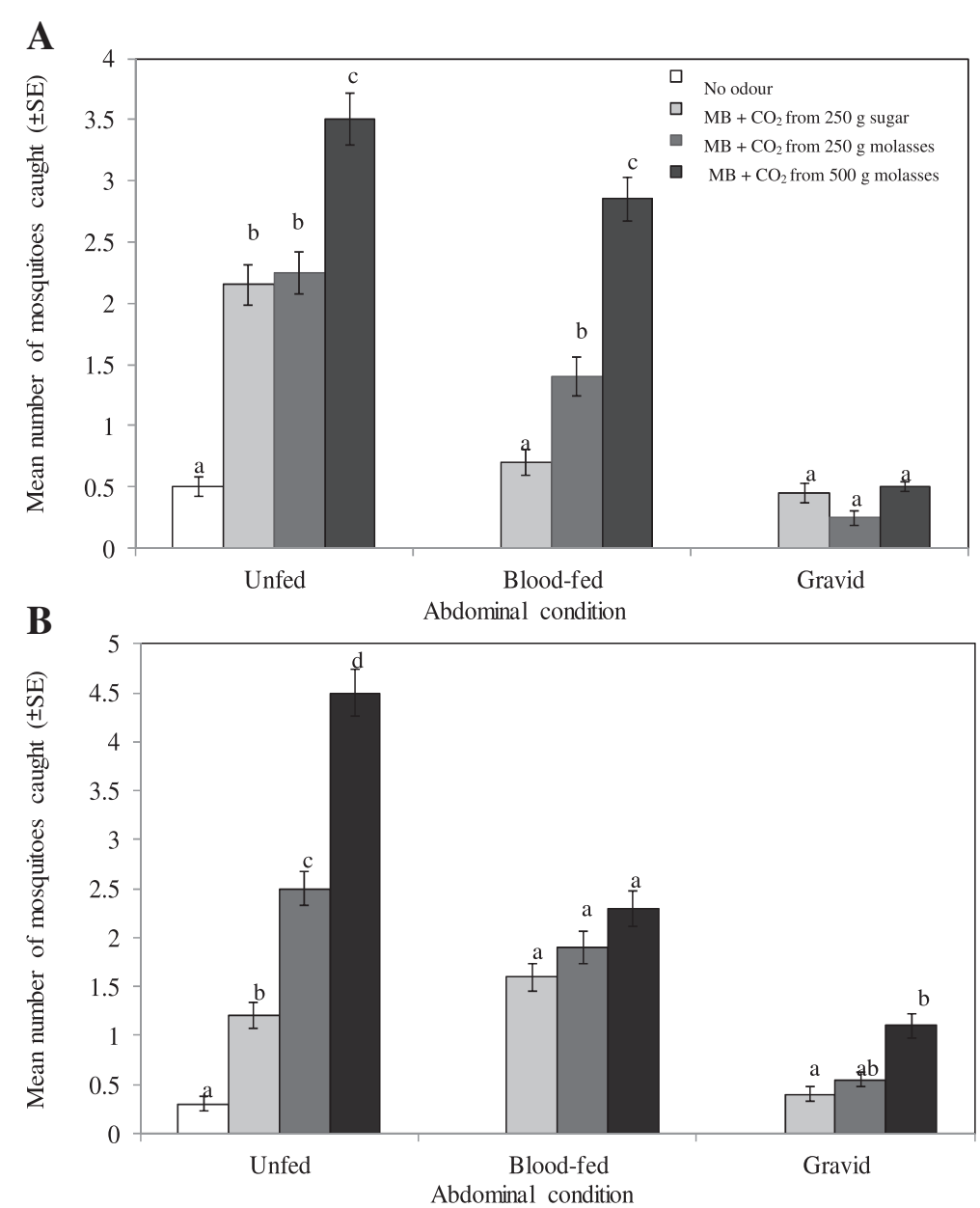

Figure 5 Mean number $( \pm$ SE) of outdoor-biting Anopheles gambiae s.l. (panel A) and Anopheles funestus (panel B) mosquitoes of different abdominal conditions (unfed, blood-fed and gravid). The mosquitoes were collected overnight in a MM-X trap without odour, baited with the Mbita blend (MB) augmented with carbon dioxide released from $250 \mathrm{~g}$ refined sugar, $250 \mathrm{~g}$ or $500 \mathrm{~g}$ molasses for 20 nights. Treatments are shown in the legend of panel A. Mean values within the same mosquito type with different letters are significantly $(P<0.05)$ different.

Culex spp. responded to the Mbita blend supplemented with $\mathrm{CO}_{2}$ released from molasses compared to a combination of the Mbita blend and $\mathrm{CO}_{2}$ derived from sugar. Total collections of wild mosquitoes comprised of $18.0 \%$ An. gambiae s.l. and $20.3 \%$ An. funestus in an unfed, blood-fed or gravid abdominal condition. Significantly more blood-fed An. gambiae s.l. were caught in traps baited with $\mathrm{CO}_{2}$ derived from fermenting molasses compared to sugar.

The results confirm that variation in the release rates of $\mathrm{CO}_{2}$ influenced by ratios of molasses and dry yeast can be sufficiently large to induce differential activation and upwind orientation of mosquitoes towards baited traps $[2,4,10]$. For example, $125 \mathrm{~g}$ molasses resulted in significantly lower release rates of $\mathrm{CO}_{2}$ lasting for periods of 320-440 min compared to a higher, stable flow rate and longer release period (over $840 \mathrm{~min}$ ) demonstrated by the sugar source. Utilization of $250 \mathrm{~g}$ molasses mixed with $17.5 \mathrm{~g}$ yeast produced $\mathrm{CO}_{2}$ for periods of 490-645 min, and this translated into significantly higher mosquito catches compared to those collected with $\mathrm{CO}_{2}$ from $250 \mathrm{~g}$ sugar with $17.5 \mathrm{~g}$ yeast. By contrast, fewer mosquitoes responded to $\mathrm{CO}_{2}$ derived from $250 \mathrm{~g}$ molasses and $35 \mathrm{~g}$ yeast, possibly because of a drastic drop in release rates resulting in an insufficient gas supply to sustain trap collections through the dawn peak biting period. It is also possible that doubling the quantity of yeast enhanced the fermentation rate of molasses, and reduced the release period thereby producing higher concentrations of $\mathrm{CO}_{2}$ with an inhibitory effect on host-seeking responses of An. gambiae [3,11,30]. Such an inhibitory effect has been reported in other studies $[30,31]$ and it is likely to account for lower mosquito responses to high release rates of $\mathrm{CO}_{2}$ from a mixture of $500 \mathrm{~g}$ molasses $+35 \mathrm{~g}$ yeast in $2 \mathrm{~L}$ water. These results indicate that although $\mathrm{CO}_{2}$ activates mosquitoes 
by inducing upwind flight, higher concentrations may reduce orientation to the source at close range $[2,32,33]$. In fact, some laboratories use high concentrations of pure $\mathrm{CO}_{2}$ to anaesthetize mosquitoes.

The release rates of $\mathrm{CO}_{2}$ produced by fermentation of $250 \mathrm{~g}(80.6 \pm 2.82 \mathrm{ml} / \mathrm{min})$ or $500 \mathrm{~g}(87.8 \pm 2.14 \mathrm{ml} / \mathrm{min})$ molasses (each mixed with $17.5 \mathrm{~g}$ yeast and $2 \mathrm{~L}$ water) were not different. However, more mosquitoes responded to $\mathrm{CO}_{2}$ produced by fermentation of $500 \mathrm{~g}$ than to $250 \mathrm{~g}$ molasses, possibly because the higher quantity of molasses provided more substrate for an extended release period of optimal $\mathrm{CO}_{2}$ concentrations. In contrast, fermentation of $250 \mathrm{~g}$ molasses, despite having a lower sugar content, showed a higher release rate of $\mathrm{CO}_{2}$ and was more attractive to An. gambiae compared to $250 \mathrm{~g}$ refined sugar. Both carbohydrate sources were mixed with the same quantity of yeast and water. This suggests that, besides $\mathrm{CO}_{2}$, yeastfermented molasses produces additional VOCs that enhance mosquito catches. The VOCs emitted by fermented sugar have been reported [11]. Whereas molasses, unlike sugar, contains a lower sugar content, it has relatively more water, solid matter, nitrogen, and minerals [34].

During the current study, the numbers of An. gambiae mosquitoes attracted to $\mathrm{CO}_{2}$ obtained from either $250 \mathrm{~g}$ or $500 \mathrm{~g}$ molasses was greatly increased in the presence of the Mbita blend. This implies that An. gambiae mosquitoes locate and orientate themselves towards odourbaited trapping systems by responding to $\mathrm{CO}_{2}$ released together with host-specific cues $[2,9,22,35]$. Thus, the results demonstrate that, although $\mathrm{CO}_{2}$ is one of the stimuli to which mosquitoes respond, trap catches are significantly increased in the presence of a plume containing human odour or synthetic odour than on its own $[2,9,35]$. It has been demonstrated that trap catches of host-seeking An. gambiae and Aedes aegypti are influenced by the structure of host odour-plumes and that the effect of $\mathrm{CO}_{2}$ on mosquito catches is concentration dependent [33]. Moreover, it was also shown that the additive effect of $\mathrm{CO}_{2}$ on worn socks is responsible for the attraction of most mosquito species in the genus Aedes, Anopheles, Coquillettidia, Culex, Culiseta, and Psorophora [8].

Similarly, the abundance and diversity of mosquitoes caught outside village houses occupied by dwellers depended on $\mathrm{CO}_{2}$ source and dose, hence corresponding to previously reported findings [3]. During the current study, a combination between $\mathrm{CO}_{2}$ produced by $500 \mathrm{~g}$ fermenting molasses and the Mbita blend led to the highest catches of unfed and blood-fed females of An. gambiae s.l.. However, the numbers of female An. gambiae s.l. collected in a trap baited with the Mbita blend augmented with $\mathrm{CO}_{2}$ from $250 \mathrm{~g}$ molasses or $250 \mathrm{~g}$ sugar were similar, indicating that both $\mathrm{CO}_{2}$ sources were equally attractive. Nonetheless, $\mathrm{CO}_{2}$ produced by $250 \mathrm{~g}$ fermenting molasses attracted similar numbers of female Culex spp. and other anopheline mosquitoes as $500 \mathrm{~g}$ molasses when presented with the Mbita blend. These observations indicate that $\mathrm{CO}_{2}$ produced by $250 \mathrm{~g}$ fermenting molasses is a suitable alternative to that produced from $250 \mathrm{~g}$ sugar. However, utilization of $500 \mathrm{~g}$ molasses would be a convenient alternative for mass-trapping of malaria vectors in situations where malaria-prone areas are endowed with sufficient resources and large scale production of sugar cane. It is then not necessary to increase the quantity of yeast, as it is, in congruence with enzyme kinetics $[11,34]$, shown that $17.5 \mathrm{~g}$ yeast added to $2 \mathrm{~L}$ water and a sugar source is sufficient for optimal $\mathrm{CO}_{2}$ production.

The attraction of significantly higher numbers of bloodfed An. gambiae s.l. mosquitoes to the Mbita blend augmented with $\mathrm{CO}_{2}$ released from molasses is a very interesting finding. Blood-fed mosquitoes are rarely caught with indoor or outdoor human landing collections [36,37]. The method is also not ethically acceptable unless collectors are given proper prophylaxis against malaria [38]. Instead, more representative samples of unfed, blood-fed and gravid females of An. gambiae s.l. as well as males are obtained by collection of resting mosquitoes $[39,40]$. This accounts for the use of resting boxes, pyrethrum spray catches, clay pots and manual aspiration of resting mosquitoes especially in studies associated with the estimation of the entomological inoculation rate [36,41]. Seemingly, cues derived from a combination of the Mbita blend and $\mathrm{CO}_{2}$ accompanied with other VOCs produced from fermenting molasses may have activated a temporal sensitivity of odour receptors thereby inducing host-seeking behaviour of unfed and blood-fed An. gambiae s.l. and An. funestus [42]. These findings are contrary to the expectations that after a blood meal, blood-feeding responses of female mosquitoes are down regulated for the next 48 to 72 hours until eggs mature and increase sensitivity of odour receptors to oviposition cues [41]. It has also been reported that small-bodied malaria vectors and those that take small-sized blood meals engage more frequently in multiple blood feeding during single gonotrophic cycles to meet their nutritional requirements [43,44]. Such feeding behaviours are more likely to increase human-vector contact and risk of malaria transmission. Whereas there were cows resting adjacent to all houses occupied by dwellers in surroundings where outdoor-biting mosquitoes were collected, utilization of different synthetic odour baits supplemented with $\mathrm{CO}_{2}$ derived from refined sugar attracted predominantly unfed An. gambiae s.l. and An. funestus in the same study site [18]. Thus, there is a high likelihood that the mosquitoes responded differently to the release rates of $\mathrm{CO}_{2}$ used to augment the Mbita blend due to genetic variability among species.

From the foregoing it is clear that attraction of blood-fed malaria vectors by synthetic odour blends supplemented 
with $\mathrm{CO}_{2}$ in conjunction with VOCs released from fermentation of molasses requires further investigation. This may provide an important resource for studies that require estimates of malaria transmission risk, as provided by the entomological inoculation rate [45]. The collection of blood-fed mosquitoes can also be used for studies of the infectious reservoir of malaria; as such mosquitoes may have fed on Plasmodium-infected hosts. Clearly the additional volatiles produced by fermentation of molasses stimulate blood-fed females to respond to the odour-baited trap, which opens up new potential for malaria-epidemiological studies. In this study no attempts were made to identify other volatile compounds produced by yeast fermentation of molasses. Likewise no efforts were made to remove/separate $\mathrm{CO}_{2}$ from the other gaseous products (if any) in order to allow investigations on the potential effect of any other products on eliciting mosquito behavioural responses. Although this research was not aimed at resolving such issues, there is a need for further investigations which should also focus on (a) determination of the relative composition of VOCs emitted by fermenting molasses and their effect on the capture rate of malaria and other mosquito vectors in different physiological conditions, (b) identification of blood meal source, and (c) how this technology may be used for estimation of entomological inoculation rate.

Whereas semi-field bioassays were conducted using An. gambiae s.s., collection of mosquitoes indoors in the same village confirmed that An. gambiae s.l. was represented by $96.7 \%$ An. arabiensis and $3.3 \%$ An. gambiae s.s. [18]. The study confirms recent findings $[11,12]$ in that, it is possible to intercept and reduce the number of malaria mosquitoes entering or leaving houses by deploying outdoor traps baited with a combination of $\mathrm{CO}_{2}$ derived from molasses and synthetic blends that mimic human odour. Deployment of this innovative technology is extremely important against outdoor-biting vectors responsible for maintaining residual transmission of malaria because intensive use of insecticide-treated nets and indoor residual spraying continues to reduce indoor transmission [46-48]. Because baiting of traps with $\mathrm{CO}_{2}$ affects host-seeking behaviour of different species of malaria vectors, further reduction of house entry of mosquitoes can be achieved by incorporation of complementary measures such as house screening [49] or application of novel repellents in a push-pull strategy [50].

\section{Conclusion}

Yeast-fermented molasses is an effective alternative source of $\mathrm{CO}_{2}$ for odour-baited trapping systems of mosquitoes as it is equally or more attractive than $\mathrm{CO}_{2}$ from fermenting sugar. This study presents an alternative use of molasses and a local solution for the development of cheaper and more sustainable lures for sampling and control of
An. gambiae s.l., An. funestus, and other human-biting mosquitoes in rural areas. This research did not expect to find blood-fed mosquitoes inside traps baited with a synthetic odour blend supplemented with a combination of $\mathrm{CO}_{2}$ and VOCs released from fermenting molasses as female mosquitoes are not attracted to their vertebrate hosts after blood feeding. Therefore, a need for further investigations on this finding is necessary.

\section{Competing interests}

The authors declare that they have no competing interests.

\section{Authors' contributions}

CKM, WT and WRM designed the study; CKM, PO and BO conducted the research; WRM and CKM analysed the data; CKM, JJAVL, WT, and WRM wrote the paper. All authors read and approved the final manuscript.

\section{Acknowledgements}

We are grateful to Mr David Odhiambo Alila for providing the laboratory-reared mosquitoes used during the semi-field experiments, while Brian Andrew Abuya and Caroline Moseti are thanked for assisting us to determine release rates of $\mathrm{CO}_{2}$. Mr Juma Wanyama and Mr Patrice Mulama of KESREF are acknowledged for determining the quality of molasses used in our experiments. We are thankful to Dr Susan A Imbahale and Mr Fred Kisanya for laboratory facilities at the Ahero Multi-purpose Development Training Institute (AMDTI) and Mr Charles Oketch for conducting field studies alongside Philemon Omusula. Our gratitude goes to household owners at Kigoche village for allowing us to conduct this study on their houses. This investigation was supported by a grant from the Foundation for the National Institutes of Health $(\mathrm{FNIH})$ through the Grand Challenges in Global Health initiative (GCGH \#121) and a sandwich PhD scholarship provided to CKM by Wageningen University, the Netherlands. CKM was hosted by ICIPE-TOC as a dissertation research internship scholar.

\section{Author details}

${ }^{1}$ International Centre of Insect Physiology and Ecology, P.O. Box 30772-00100, GPO, Nairobi, Kenya. ${ }^{2}$ Laboratory of Entomology, Wageningen University, PO Box 8031, 6700 EH Wageningen, The Netherlands. 3School of Biological Sciences, University of Nairobi, PO Box 30197-00100, GPO, Nairobi, Kenya.

Received: 25 February 2014 Accepted: 18 April 2014

Published: 27 April 2014

\section{References}

1. Takken $\mathrm{W}$ : The role of olfaction in host-seeking of mosquitoes: a review. J Trop Insect Sci 1991, 12:287-295.

2. Gillies MT: The role of carbon dioxide in host-finding by mosquitoes (Diptera: Culicidae): a review. Bull Entomol Res 1980, 70:525-532.

3. Costantini C, Gibson G, Sagnon N, Della Torre A, Brady J, Coluzzi M: Mosquito responses to carbon dioxide in a west African Sudan savanna village. Med Vet Entomol 1996, 10:220-227.

4. Takken W, Knols BGJ: Odor-mediated behavior of Afrotropical malaria mosquitoes. Ann Rev Entomol 1999, 44:131-157.

5. Gibson G, Torr SJ: Visual and olfactory responses of haematophagous Diptera to host stimuli. Med Vet Entomol 1999, 13:2-23.

6. Mboera LEG, Knols BGJ, Braks MAH, Takken W: Comparison of carbon dioxide-baited trapping systems for sampling outdoor mosquito populations in Tanzania. Med Vet Entomol 2000, 14:257-263.

7. Kline DL: Semiochemicals, traps/targets and mass trapping technology for mosquito management. J Am Mosq Control Assoc 2007, 23:241-251.

8. Kline D, Lemire G: Evaluation of attractant-baited traps/targets for mosquito management on Key Island, Florida, USA. J Vector Ecol 1998, 23:171-185

9. Spitzen J, Smallegange RC, Takken W: Effect of human odours and positioning of $\mathrm{CO}_{2}$ release point on trap catches of the malaria mosquito Anopheles gambiae sensu stricto in an olfactometer. Physiol Entomol 2008, 33:116-122.

10. Cardé RT, Gibson G: Host finding by female mosquitoes: mechanisms of orientation to host odours and other cues. In Olfaction in vector-host 
interactions. Edited by Takken W, Knols BGJ. Wageningen: Wageningen Academic Publishers; 2010:115-142.

11. Smallegange RC, Schmied HW, Van Roey JK, Verhulst NO, Spitzen J, Mukabana WR, Willem T: Sugar-fermenting yeast as an organic source of carbon dioxide to attract the malaria mosquito Anopheles gambiae. Malar J 2010, 9:292.

12. Jawara M, Taiwo S, Amargaret P, David J, Renate CS, Willem T, David JC: Field testing of different chemical combinations as odour baits for trapping wild mosquitoes in The Gambia. PLoS One 2011, 6:e19676.

13. Njiru B, Mukabana W, Takken W, Knols B: Trapping of the malaria vector Anopheles gambiae with odour-baited MM-X traps in semi-field conditions in western Kenya. Malar J 2006, 5:39.

14. Qiu YT, Smallegange RC, Braak CJF, Spitzen J, Van Loon JJA, Jawara M, Milligan P, Galimard AM, Van Beek TA, Knols BGJ, Takken W: Attractiveness of MM-X traps baited with human or synthetic odor to mosquitoes (Diptera: Culicidae) in The Gambia. J Med Entomol 2007, 44:970-983.

15. Mboera LEG, Knols BGJ, Takken W, Della Torre A: The response of Anopheles gambiae s.l. and Anopheles funestus (Diptera: Culicidae) to tents baited with human odour or carbon dioxide in Tanzania. Bull Entomol Res 1997, 87:173-178.

16. Okumu FO, Killeen GF, Ogoma S, Biswaro L, Smallegange RC, Mbeyela E, Titus E, Munk C, Ngonyani H, Takken W, Hassan M, Mukabana WR, Moore SJ: Development and field evaluation of a synthetic lure that is more attractive than humans. PLoS One 2010, 5:e8951.

17. Okumu FO, Madumla E, John A, Lwetoijera D, Sumaye R: Attracting, trapping and killing disease-transmitting mosquitoes using odor-baited stations -The Ifakara odor-baited stations. Parasit Vectors 2010, 3:12.

18. Mukabana WR, Mweresa CK, Otieno B, Omusula P, Smallegange RC, van Loon JJA, Takken W: A novel synthetic odorant blend for trapping of malaria and other African mosquito species. J Chem Ecol 2012, 38:235-244.

19. Burkett DA, Lee WJ, Lee KW, Kim HC, Lee HI, Lee JS, Shin EH, Wirtz RA, Cho HW, Claborn DM, Coleman RE, Kim WY, Klein TA: Late season commercial mosquito trap and host seeking activity evaluation against mosquitoes in a malarious area of the Republic of Korea. J Parasit 2002, 40:45-54.

20. Oli K, Jeffery J, Vythilingam I: A comparative study of adult mosquito trapping using dry ice and yeast generated carbon dioxide. Trop Biomed 2005, 22:249-251.

21. Kline DL: Traps and trapping techniques for adult mosquito control. J Am Mosa Control Assoc 2006, 22:490-496.

22. Verhulst NO, Mukabana WR, Takken W, Smallegange RC: Human skin microbiota and their volatiles as odour baits for the malaria mosquito Anopheles gambiae s.s. Entomol Exp Appl 2011, 139:170-179.

23. Bukhari T, Takken W, Andrew KG, Koenraadt JMC: Efficacy of aquatain, a monomolecular film for the control of malaria vectors in rice paddies. PLoS One 2011, 6:e21713.

24. Mathenge EM, Misiani GO, Irungu LW, Ndegwa PN, Smith LW, Killeen GF, Knols BGJ: Comparative performance of the Mbita trap, CDC light trap and the human landing catch in the sampling of Anopheles arabiensis: an funestus and culicine species in a rice irrigation in western Kenya. Malar J 2005, 4:7.

25. Mukabana WR, Mweresa CK, Otieno B, Omusula P, Orindi B, Smallegange RC, van Loon JJA, Takken W: Evaluation of low density polyethylene and nylon for delivery of synthetic mosquito attractants. Parasit Vectors 2012 5:202.

26. Schmied W, Takken W, Killeen G, Knols BGJ, Smallegange RC: Evaluation of two counterflow traps for testing behaviour-mediating compounds for the malaria vector Anopheles gambiae s.s. under semi-field conditions in Tanzania. Malar J 2008, 7:230.

27. Verhulst NO, Mbadi P, Bukovinszkiné-Kiss G, Mukabana WR, van Loon JJA Takken W, Smallegange RC: Improvement of a synthetic lure for Anopheles gambiae using compounds produced by human skin microbiota. Malar J 2011, 10:28.

28. Gillies MT, Coetzee M: A supplement to the Anophelinae of Africa South of the Sahara. Johannesburg: South African Institute for Medical Research; 1987.

29. WHO: Manual on practical entomology in malaria: part II, methods and techniques. Geneva, Switzerland: WHO Division of Malaria and other Parasitic Diseases; 1975.

30. Lefèvre T, Gouagna LC, Dabire KR, Elguero E, Fontenille D, Costantini C, Thomas F: Evolutionary lability of odour-mediated host preference by the malaria vector Anopheles gambiae. Trop Med Int Hlth 2009, 14:228-236.
31. Takken W, Kline D: Carbon dioxide and 1-octen-3-ol as mosquito attractants. J Am Mosq Control Assoc 1989, 5:311-316.

32. Takken W, Dekker T, Wijnholds YG: Odor-mediated behavior of Anopheles gambiae s.s. Giles and An. stephensi Liston in response to carbon dioxide, acetone and 1-octen-3-ol. J Insect Behav 1997, 10:395-407.

33. Dekker T, Takken W, Cardé RT: Structure of host-odour plumes influences catch of Anopheles gambiae s.s. and Aedes aegypti in a dual-choice olfactomer. Physiol Entomol 2001, 26:124-134.

34. Patrascu E, Rapeanu G, Bonciu C, Hopulele T: Bioethanol production from molasses by different strains of Saccharomyces cerevisiae. AUDJG 2009. Fascicle VI - Food Technology, New Series Year III (XXXIII).

35. Dekker T, Steib B, Cardé RT, Geier M: L-lactic acid: a human-signifying host cue for the anthropophilic mosquito Anopheles gambiae. Med Vet Entomol 2002, 16:91-98.

36. Dia I, Diallo D, Duchemin J, Konate YB, Costantini C, Diallo M: Comparisons of human-landing catches and odor-baited entry traps for sampling malaria vectors in Senegal. J Med Entomol 2005, 42:104-109.

37. Le Goff G, Carnevale P, Fondjo E, Robert V: Comparison of three sampling methods of man-biting anophelines in order to estimate the malaria transmission in a village of south Cameroon. Parasite 1997, 4:75-80.

38. Gimnig JE, Walker ED, Otieno P, Kosgei J, Olang G, Ombok M, Williamson J, Marwanga D, Abongo D, Desai M, Kariuki S, Vulule J, Hamel M, Lobo NF, Vulule J, Bayoh MN: Incidence of malaria among mosquito collectors conducting human landing catches in western Kenya. Amer J Trop Med Hyg 2013, 88:301-308.

39. Joshi GP, Fontaine RE, Pradhan GD: The CDC battery-operated light trap for assessment of An. gambiae and An. funestus in a WHO stage VII insecticide trial, Kisumu, Kenya. WHONBC 1975, 75:578.

40. Bentley MT, Kaufman PE, Kline DL, Hogsette JA: Response of adult mosquitoes to light-emitting diodes placed in resting boxes and in the field. J Am Mosa Control Assoc 2009, 25:285-291.

41. Mboera LEG: Sampling techniques for adult Afrotropical malaria vectors and their reliability in the estimation of entomological inoculation rate. Tanzania Health Res Bull 2005, 7:117-124.

42. Qiu YT, van Loon JJA: Olfactory physiology of blood-feeding vector mosquitoes. In Olfaction in vector-host interactions. Edited by Takken W, Knols BGJ. Wageningen: Wageningen Academic Publishers; 2010:39-61.

43. Foster WA, Takken W: Nectar-related vs. human related volatiles: behavioural response and choice by female and male Anopheles gambiae (Diptera: Culicidae) between emergence and first feeding. Bull Entomol Res 2004, 94:145-157.

44. Scott TW, Takken W: Feeding strategies of anthropophilic mosquitoes result in increased risk of pathogen transmission. Trends Parasito/ 2012 28:114-121.

45. Smith T, Maire N, Dietz K, Gf K, Vounatsou P, Molineaux L, Tanner M: Relationship between the entomological inoculation rate and the force of infection for Plasmodium falciparum malaria. Am J Trop Med Hyg 2006, 2006(75):11-18.

46. Antonio-Nkondjio OC, Kera CH, Simard F, Awono-Ambene P, Chouaibou M Tchuinkam T, Fontenille D: Complexity of the malaria vectorial system in Cameroon: contribution of secondary vectors to malaria transmission. J Med Entomol 2006, 43:1215-1221.

47. Russell TL, Govella NJ, Azizi S, Drakeley CJ, Kachur SF, Killeen GF: Increased proportions of outdoor feeding among residual malaria vector populations following increased use of insecticide-treated nets in rural Tanzania. Malar J 2011, 10:80.

48. Govella NJ, Ferguson $\mathrm{H}$ : Why use of interventions targeting outdoo biting mosquitoes will be necessary to achieve malaria elimination. Front Physio 2012, 3:199-205.

49. Lindsay SW, Emerson PM, Charlwood JD: Reducing malaria by mosquitoproofing houses. Trends Parasitol 2002, 18:510-514

50. Takken W: Push-pull strategies for vector control. Malar J 2010, 9:116.

\section{doi:10.1186/1475-2875-13-160}

Cite this article as: Mweresa et al.: Molasses as a source of carbon dioxide for attracting the malaria mosquitoes Anopheles gambiae and Anopheles funestus. Malaria Journal 2014 13:160. 